\section{P173 THE ROLE OF TRANSCUTANEOUS CARBON DIOXIDE MONITORING IN ACUTE NON-INVASIVE VENTILATION}

J Van Oppen, P Daniel, M Sovani; Queens Medical Centre, Nottingham, England

\subsection{6/thoraxjnl-2013-204457.324}

Background Transcutaneous carbon dioxide monitoring is rarely used in the acute hospital setting, where samples of arterial blood are used to measure pCO2. This is a pilot observational study to assess the role of transcutaneous $\left(\mathrm{p}_{\mathrm{tc}} \mathrm{CO}_{2}\right)$ versus arterial $\left(\mathrm{p}_{\mathrm{a}} \mathrm{CO}_{2}\right)$ monitoring during acute NIV, both to calculate $\mathrm{pH}$ and to guide therapy.

Methods Ten patients with acute hypercapnic respiratory failure were recruited. All had arterial lines placed for guiding acute NIV therapy. $\mathrm{p}_{\mathrm{tc}} \mathrm{CO}_{2}$ was monitored for 12 hours (Radiometer TOSCA TCM4) and compared to measures of $\mathrm{p}_{\mathrm{a}} \mathrm{CO}_{2}$ from samples taken from the arterial lines. Non-invasive $\mathrm{pH}_{\mathrm{tc}}$ was calculated from $\mathrm{p}_{\mathrm{tc}} \mathrm{CO}_{2}$. Agreements between $\mathrm{pCO}_{2}$ and $\mathrm{pH}$ methods were assessed using Bland-Altman analysis and regression. The potential for guiding acute NIV therapy based on transcutaneous data was assessed and pain scores for each method were compared using the Wilcoxon signed rank test.

Results Mean bias between $\mathrm{p}_{\mathrm{a}} \mathrm{CO}_{2}$ and $\mathrm{p}_{\mathrm{tc}} \mathrm{CO}_{2}$ was $-0.31(95 \%$ CI 0.98$) \mathrm{kPa}, \mathrm{R}^{2}=0.79(\mathrm{p}<0.0001) \cdot \mathrm{p}_{\mathrm{tc}} \mathrm{CO}_{2}$ followed the same time trend as $\mathrm{p}_{\mathrm{a}} \mathrm{CO}_{2}$. Mean $\mathrm{pH}$ bias was not statistically significant at 0.006 (95\% CI 0.116), $R^{2}=0.64$ ( $\left.p<0.0001\right)$. If based on transcutaneous data only, clinical decisions would have been unchanged in nine out of ten patients. Transcutaneous readings were also less painful $(\mathrm{p}<0.001)$ and preferred by patients.

Conclusion This pilot study demonstrates the potential for using transcutaneous $\mathrm{pCO}_{2}$ monitoring to calculate $\mathrm{pH}$ and guide therapy, in the acute care setting. $\mathrm{p}_{\mathrm{tc}} \mathrm{CO}_{2}$ shows promise in replacing arterial blood gases, in acute hypercapnic respiratory failure.

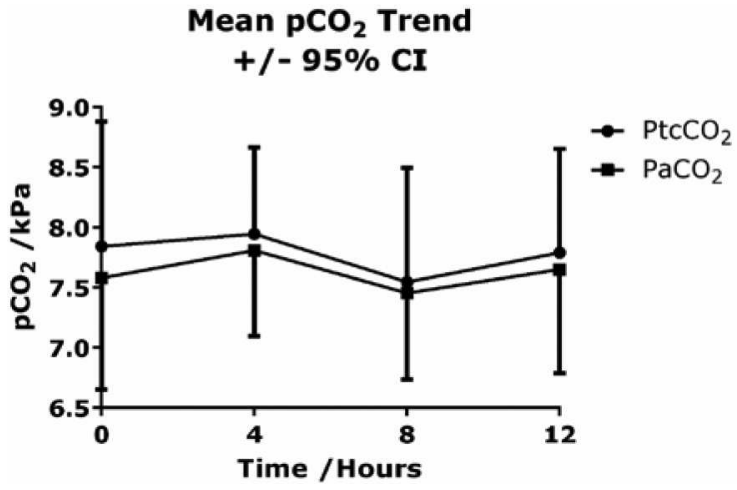

Abstract P173 Figure 1.

\section{P174 REDUCTION IN HOSPITAL ADMISSIONS IN COPD PATIENTS FOLLOWING DOMICILIARY BIPAP}

A Fazleen, R Mirza, B Prathibha; William Harvey Hospital, Ashford, United Kingdom

\subsection{6/thoraxjnl-2013-204457.325}

Introduction COPD is a condition with multiple implications to the sufferer in terms of disability and high mortality, and one that often necessitates multiple hospital admissions, resulting in further distress to the patient as well as increased healthcare costs. Bi-level positive airway pressure (BIPAP) has long been used to treat patients with acute exacerbations of COPD in hosiptal settings. We aim to decipher if institution of BIPAP reduces the number of hospital admissions in patients with COPD.

Method We used a regional database to gather information on patients on domicilliary BIPAP in the region, and identified the number of patients with a primary diagnosis of COPD. We then used the electronic discharge notification software in hospitals in the region to identify the number of hospital admissions in these patients before and after the institution of BIPAP, within a one-year period. We used 2011 as the base year, i.e., we collected data from patients who were initiated on BIPAP in 2011, and determined the number of admissions the year prior to, and the year following, initiation of BIPAP.

Results On the database studied, 317 patients were on domiciliary BIPAP, 112 of which were secondary to COPD (35.33\% of the total database). A total of 23 patients were commenced on BIPAP in 2011. The number of admissions per year prior to initiating BIPAP ranged from 0 to 4 , with a total of 39 admissions among all patients, equating to a mean of 1.70 admissions per patient. This reduced to 14 in the year following BIPAP, with an average of 0.61 admissions per patient, reducing the number of admissions by almost two-thirds.

Conclusion These findings suggest that the use of domiciliary BIPAP reduces hospital admissions in patients with COPD, thereby improving, at least partially, their quality of life. It also highlights the importance of a dedicated centre for managing patients on domiciliary BIPAP, as this database reflected the work of a single respiratory centre within the region specialising in managing patients requiring domiciliary BIPAP, thereby providing standardised care.

\section{P175 HOME MECHANICAL VENTILATION (HMV): AN EXPANDING SERVICE IN ACUTE HOSPITALS}

CA Lynch, 0 O'Sullivan, N Santana-Vaz, K Morley, B Beauchamp, A Oakes, R Mukherjee; Birmingham Heartlands Hospital, Birmingham, United Kingdom

10.1136/thoraxjnl-2013-204457.326

Background HMV/domiciliary non-invasive ventilation (NIV) is being increasingly used to treat chronic ventilatory failure, particularly due to obesity and neuromuscular conditions. In patients attending an acute hospital, most domiciliary NIVs are set up at the end of an acute episode of admission with hypercapnic acidotic respiratory failure but over time, as more at-risk patients come under surveillance for respiratory failure, we hypothesised that a unit supervising domiciliary NIV/HMV is expected to do more elective set-ups.

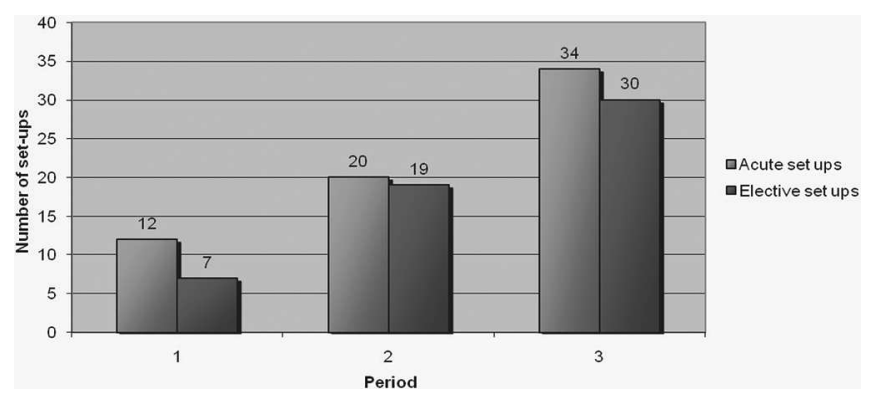

Abstract P175 Figure 1. HMV set-ups: Elective vs Acute. 